\author{
Maria - Monica (HARALAMBIE) POPESCU, PhD Student \\ The Bucharest University of Economic Studies \\ E-mail: haralambie.monica@gmail.com \\ Professor Bogdan - Stefan IONESCU, PhD \\ The Bucharest University of Economic Studies \\ E-mail: ionescub@gmail.com
}

\title{
IFRS 9 BENCHMARKING TEST: TOO COMPLICATED TO WORTH DOING IT?
}

\begin{abstract}
Introduction of IFRS 9 "Financial instruments" was one of the responses of the G20 world leaders to global financial crisis. Even if it was meant to reduce the complexity of measuring financial instruments, the reality in the previous 3-4 years before implementation revealed that the stakeholders, and especially the financial institutions, which are heavily affected by these changes, found IFRS 9 difficult to understand, costly to implement and involving a high degree of professional judgment. One of the key areas which became more complicated following IFRS 9 transition was classification of financial assets, as a result of changes in business models or modifications of contractual cash flows characteristics of the instrument.

In this paper, we discuss the benchmarking test required by IFRS 9 in situations in which the time value of money element included in the interest of a financial asset (a loan) is modified and propose two modelling techniques for performing this test: forward interest rates and Vasicek interest rate model.

Keywords:IFRS 9, Benchmark Cashflow Test, Amortised Cost, Fair Value, Forward Interest Rates, Vasicek Interest Rate Model, Credit Institutions, Banks.

\section{JEL Classification:C10,G12, G17, G21, M41}

\section{Introduction}

Accounting for financial instruments was considered over time one of the most complex areas of International Financial Reporting Standards (IFRS). Dealing with the rules regarding initial classification, and subsequent measurement of financial instruments, IAS 39 and its further amendments with its concept of "incurred loss model" was not sufficient to capture the procyclicality of the economic environment and the market downturn that followed starting with end of $2007{ }^{1}$. It was argued that the approach followed by the financial institutions in relation to
\end{abstract}

${ }^{1}$ IFRS 9, Impairment and Procyclicality: Is the cure worse than the disease? Jane Hronsky The University of Melbourne and David Robinson Ernst \& Young1

DOI: 10.24818/18423264/53.1.19.14 
Maria - Monica (Haralambie) Popescu, Bogdan - Stefan Ionescu

risk management framework was "too little, too late" in the context of the global financial crisis.

The criticism of IAS 39's incurred loss model and fair value accounting, led to a series of discussions initiated by $\mathrm{G}_{2} \mathrm{O}^{2}$, with the view of reducing the complexity of the accounting standards for financial instruments. Other objectives of this process included increasing the involvement of a different range of stakeholders in the process of setting the accounting standards and subsequently, improving the transparency and clarity of the risk management framework from outside the financial institutions and improving the methodology in relation to loan loss provisioning by incorporating credit information from inside and outside of the organization.

Based on these objectives, the International Accounting Standards Board (IASB) issued several exposure drafts for a new standard replacing the old 2001 IAS 39, drafts which were extensively debated by a wide range of stakeholders, from banks themselves, to regulators and auditors. As a result of these discussions, IFRS 9 "Financial instruments" came into force starting with 1 January 2018 and changed not only the classification of financial assets, but also the way banks assess the expected credit losses in relation to the financial instruments.

The new IFRS 9 standard approaches the financial instruments' accounting from two different perspectives: classification \&measurement and impairment of financial assets and financial liabilities.

In a nutshell, the classification and measurement of the investments in debt instruments will be dictated by the assessment of the entity's business model for managing the instrument and the contractual cash flows characteristics of the instrument (called Solely Payments of Principal and Interest test - "SPPI").The underlying principle of IFRS 9 classification \& measurement is that a debt instrument passes SPPI test if give rise to cash flows that are solely payments of principal and interest on the principal amount outstanding. In this respect, interest should represent consideration for time value of money, credit risk and liquidity risk of the financial institution, plus, if the case, a reasonable compensation element (i.e. a margin of profit on the financial asset).

Our analysis will be centered on the time value of money component from interest, or, put simply, if this element provides consideration only for the passage of time, and not for other costs associated with holding a specific financial asset, in this case, a loan granted by a financial institution to a client.

\footnotetext{
2 The G20, Declaration on Strengthening the Financial System, London Summit, 2 April 2009
} 
IFRS 9 Benchmarking Test: Too Complicated to Worth Doing It?

IFRS 9 refers to situations in which the time value of money element can be modified if the loan's interest has a variable component (e.g. ROBOR, EURIBOR, LIBOR etc.) and the frequency of the reset does not match the tenor of the interest rate. For example, a loan with an interest composed of ROBOR $3 \mathrm{M}+$ margin is reset every month, instead of every three months, or a loan with interest rate composed of EURIBOR $3 \mathrm{M}+$ margin is calculated as the average of 3-month EURIBOR from the last month.

If the time value of money element is modified, the bank could perform a qualitative or quantitative analysis, called benchmark test, in order to assess the modification. If the benchmark test result indicates that the modification is not significantly different, the SPPI test could still be met.

The benchmark test principle considers assessing the cash flows characteristic of the underlying instrument with the ones of a "perfect" instrument, i.e. the cash flows of an instrument that would arise if the time value of money element was not modified. Consistent with our example above, the cash flows arising from the loan with interest composed of ROBOR $3 \mathrm{M}+$ margin resetted every month will be compared against the cash flows of the same loan with interest composed of ROBOR $1 \mathrm{M}+$ margin (in order to obtain the matching of the tenor of the interest with the frequency of the reset).In the other example with the loan with interest rate calculated as the average of EURIBOR 3M from the last month, a qualitative assessment could be sufficient, given the expectation that the reference rate should not to fluctuate significantly during this short time frame of 3 months.

IFRS 9 does not define the terms "modified" or "perfect" or "significantly different", neither prescribe a single way of performing the benchmark test. As such, professional judgment will be required on an instrument-by-instrument basis in order to determine an appropriate method for assessing the modification and in order to conclude on the result of the assessment. However, there are some factors which need to be considered when performing the benchmark test, which are presented in the following table:

Table 1: Factors which need to be considered when performing the benchmark test

\begin{tabular}{|l|l|}
\hline Factor & Description \\
\hline Instrument-by- & The objective of the benchmark test is to assess how \\
instrument basis & $\begin{array}{l}\text { different are the cash flows arising from the modified } \\
\text { instruments versus the ones arising from a perfect } \\
\text { instrument. As such, the conclusion should be drawn on } \\
\text { an instrument-by-instrument basis, and not on a portfolio } \\
\text { level or over the entire sample of loans which present } \\
\text { features of modification in the time value of money } \\
\text { component; }\end{array}$ \\
\hline
\end{tabular}


Maria - Monica (Haralambie) Popescu, Bogdan - Stefan Ionescu

\begin{tabular}{|c|c|}
\hline Reporting period & $\begin{array}{l}\text { The IFRS } 9 \text { SPPI test must be performed at initial } \\
\text { recognition of the debt instrument analyzed. Similarly, the } \\
\text { benchmark test will be done at initial recognition, but will } \\
\text { consider the effect of the modification of the time value of } \\
\text { money component not only cumulatively over the life of } \\
\text { the instrument, but also in each reporting period relevant } \\
\text { for the credit institution. By performing only the } \\
\text { cumulative assessment, the positive differences arisen in } \\
\text { one period could be "diluted" by the negative differences } \\
\text { in another period, which is not an appropriate approach; }\end{array}$ \\
\hline $\begin{array}{l}\text { Reasonable } \\
\text { scenarios }\end{array}$ & $\begin{array}{l}\text { IFRS } 9 \text { requires the financial entity to consider "only } \\
\text { reasonably possible scenarios instead of every possible } \\
\text { scenario", which should incorporate previously observed } \\
\text { and unobserved outcomes that are reasonably possible in } \\
\text { the future. As such, an appropriate benchmark test for an } \\
\text { instrument with a long tenor will consider analysis over an } \\
\text { entire economic cycle including boom and recession } \\
\text { periods, if such instances were observed in the past and } \\
\text { are reasonably expected to repeat in the future; }\end{array}$ \\
\hline $\begin{array}{l}\text { Exclusion or } \\
\text { inclusion of } \\
\text { principal amounts }\end{array}$ & $\begin{array}{l}\text { Since the objective of the benchmark test is to assess the } \\
\text { modification in the time value of money element, this } \\
\text { assessment will usually consider only the interest } \\
\text { component of the loan installment. However, there are } \\
\text { instances when professional judgment is required to be } \\
\text { exercised to assess the magnitude of the adjustments to } \\
\text { the time value of money component, when a product, such } \\
\text { as an amortising loan, has monthly payments including } \\
\text { both principal and interest, which cannot be separated; } \\
\text { and }\end{array}$ \\
\hline $\begin{array}{l}\text { Relative versus } \\
\text { absolute threshold }\end{array}$ & $\begin{array}{l}\text { in determining whether the cash flows of the "modified" } \\
\text { instrument are "significantly different" from the cash } \\
\text { flows of the "perfect" instrument, the financial institution } \\
\text { can use either a relative analysis, meaning computing if } \\
\text { the percentage of the analyzed instrument cash flows from } \\
\text { the benchmark instrument's cash flows exceeds X\%, or an } \\
\text { absolute measure, which takes into account the size of the } \\
\text { instrument's total cash flows. }\end{array}$ \\
\hline
\end{tabular}

This article's objective is to compare past and future cash flows of a loan originated on 2005, up until maturity (up to 2047 for the Vasicek interest rate forecast), which has a variable reference rate different than the characteristics of its benchmark. The premise of this test is to demonstrate that the cash flows of the modified instruments compared with the cash flows of a "perfect" instrument (its 
IFRS 9 Benchmarking Test: Too Complicated to Worth Doing It?

benchmark) are not significantly different in the analyzed period. If so, the loan could continue to be measured at amortised cost, which is a key objective of a financial institution in respect of its loan portfolio, in order to avoid the volatility in profit and loss account caused by changes in fair value.

\section{Interest rate modelling}

We have developed a tool which compares EURIBOR 3-months rates with monthly resetting versus EURIBOR 1-month rates with monthly resetting.

The case analyzed is a retail loan in amount of EUR 130,000 granted on 1March-2005, with maturity on 28-Feb-2035 and interest rate of EURIBOR 3M plus margin of $2.5 \%$ (hereinafter referred as "modified instrument"). The benchmark instrument is a loan with the same characteristics, but the interest rate is EURIBOR $1 \mathrm{M}$ plus margin of $2.5 \%$ (hereinafter referred as "benchmark instrument").

Firstly, we will compare the cash flows generated by the modified instrument with the cash flows generated by the benchmark instrument in the period between origination date (1 March 2005) and 31 December 2017.

Secondly, in order to estimate the future cash flows between 31 December 2017 and maturity date we will use two modelling techniques, namely forward interest rates and Vasicek interest rate model.

\section{Historical period between origination date and 31 December 2017}

We have extracted from Bloomberg $1 \mathrm{M}$ and 3M EURIBOR rates for the period between origination date (1 March 2005) and the date of our analysis (i.e. 31 December 2017 for this model).

\section{Forward interest rates}

We have extracted from Bloomberg $1 \mathrm{M}$ and $3 \mathrm{M}$ monthly forward rates for a period up to 6 February2034 (derived from the EUR swap curve) (end of day ASK/LAST values). After this date, we have assumed in our model that the curve is flat (last forward rates Euribor 1M - 1.98\% and Euribor 3M - 2.04\%).

\section{Vasicek interest rate model}

When analyzing the evolution of EURIBOR reference rate for such a long period of 30 years, we can observe a jump from $-0.374 \%$ to $5.050 \%$ in case of EURIBOR $1 \mathrm{M}$ (respectively from $-0.3310 \%$ to $5.277 \%$ in case of EURIBOR $3 \mathrm{M}$ ) due to unexpected events and cyclicality of the economy. And the peak between min and max can be even higher in case of interest rates linked to more volatile currencies (such as ROBOR or CHF LIBOR). Most economists agree that the interest rates will return to their long-term average once the cause of the unexpected event is removed. As such, when modelling future interest rates, some practitioners use the geometric Brownian motion (GBM) in order to simulate 
Maria - Monica (Haralambie) Popescu, Bogdan - Stefan Ionescu

simple paths. However, the expected returns of the GBM model are independent of the value of the process and in such a situation, a jump to 5\% for the interest rate would be accepted as normal in the model and the GBM would proceed in a random manner from there.

As it is economically unreasonable to think that interest rates can "wander-off to infinity" or become arbitrarily large, GBM suffers of some criticism.

Some of these shortcomings are solved by a model, which considers a random variable, but with a mean reversion function modelled mathematically. The Vasicek model was chosen, since it allowed us to exercise some "control" over the randomness of the shocks at each time steps using a mean reversion factor.

The Vasicek interest rate model assumes that the movement of an interest rate is derived as a function of market risk, time and a mean reversion factor (the longterm mean we assume the interest rate will revert to). Differently from GBM model, Vasicek interest rate model assumes that the interest rate changes are not completely independent and that the trajectory of the expected interest rate will evolve around this long-term mean, considering at the same time a shock factor (volatility).

The Vasicek interest rate model values the instantaneous interest rate using equation 1:

$$
d r_{t}=a\left(b-r_{t}\right) d t+s d W_{t}
$$

where:

- $\mathrm{W}_{\mathrm{t}}$ is the random market risk (represented by the Wiener process) (we used the Excel function RAND() - a random variable from the normal distribution with mean 0 and standard deviation of 1

- $\quad t$ represents time - in this case 1 Month (1/12)

- $a\left(b-r_{t}\right)$ represents the expected change in the interest rate at $t$ (drift factor):

$\circ \mathrm{a}$ is the speed of reversion (Slope of the function or expert assumption)

$\circ \quad b$ is the long-term level of the mean (estimated as documented below using regression analysis - Intercept of the function, or expert assumption)

- $\mathrm{s}$ is the volatility at the time (monthly)

Our approach in computing the parameters which were used in the Vasicek interest rate model started from the assumption that the $3 \mathrm{M}$ and 1M EURIBOR rates are "going together", where $3 \mathrm{M}$ is usually represented by the $1 \mathrm{M}$ rate plus a spread which varies within time. As such, we chose to model $1 \mathrm{M}$ rates and the $1 \mathrm{M}$ $3 \mathrm{M}$ spread. As a result, at each point in time, the $3 \mathrm{M}$ rate is simply the estimated $1 \mathrm{M}$ rate adjusted by the estimated spread. 
IFRS 9 Benchmarking Test: Too Complicated to Worth Doing It?

The mean regression was estimated in a relatively simple and robust manner, by regressing absolute price changes on the previous price levels.

The relevant parameters of the regression were estimated as follows:

- the mean reversion speed is the negative of the slope - we have used Excel Function $=\operatorname{SLOPE}(\mathrm{Y}: \mathrm{Y}, \mathrm{X}: \mathrm{X})$, where $\mathrm{Y}: \mathrm{Y}$ represents EURIBOR $1 \mathrm{M}$ in $\mathrm{t}$ minus EURIBOR $1 \mathrm{M}$ in $\mathrm{t}-1$ and $\mathrm{X}: \mathrm{X}$ represents EURIBOR $3 \mathrm{M}$ in $\mathrm{t}$;

- the intercept - we have used Excel Function =INTERCEPT(Y:Y,X:X), where $\mathrm{Y}: \mathrm{Y}$ represents EURIBOR $1 \mathrm{M}$ in $\mathrm{t}$ minus EURIBOR $1 \mathrm{M}$ in $\mathrm{t}-1$ and $\mathrm{X}: \mathrm{X}$ represents EURIBOR $3 \mathrm{M}$ in $\mathrm{t}$;

- the long-term mean represents the ratio between the intercept and the mean reversion speed;

- the percentage volatility is the ratio between STEYX $1.53 \%$ and the longterm mean;

- the equilibrium rate (long-run mean) of the spread was estimated using a weighted mean with a decay factor of 0.985 , hence giving more importance to recent spreads.

As explained above, in contrast with the "random walk" process, where the price changes were independent through time, a mean reverting process like this one modelled by us, is characterized by prices that have some degree of "memory" about the previous price changes. The mean price levels will be our best forecast of future price levels.

The parameters resulted from our computation were the following:

Table 2: Parameters for modelling EURIBOR 1M using Vasicek interest rate model

\begin{tabular}{|l|l|l|}
\hline Initial Interest rate (last) & $-0.37 \%$ & $\begin{array}{l}\text { Last observed EURIBOR 1M value at } \\
\text { the date of our calculation (i.e.22-Jun- } \\
2017 \text { for Vasicek IR model) }\end{array}$ \\
\hline Total time (years) & 30 & Tenor of the loan facility \\
\hline $\begin{array}{l}\text { Strength of mean } \\
\text { reversion }\end{array}$ & 0.01 & The mean reversion speed \\
\hline Equilibrium rate & $0.42 \%$ & Equilibrium rate \\
\hline Volatility & $1.53 \%$ & STEYX \\
\hline Time Step & 0.0833 & $\begin{array}{l}\text { As we will estimate the daily interest rate } \\
\text { values, we have computed the time step } \\
\text { as the ratio between 30 years and } \\
\text { (assumed) 360 days in a year. }\end{array}$ \\
\hline
\end{tabular}


Maria - Monica (Haralambie) Popescu, Bogdan - Stefan Ionescu

Table 3: Parameters for modelling the spread between EURIBOR 1M and EURIBOR 3M using Vasicek interest rate model

\begin{tabular}{|l|l|l|}
\hline Initial Interest rate (last) & $0.05 \%$ & $\begin{array}{l}\text { Last observed value of the spread } \\
\text { between EURIBOR 3M and EURIBOR } \\
1 \mathrm{M} \text { at the date of our calculation (i.e. 22- } \\
\text { Jun-2017 for Vasicek IR model) }\end{array}$ \\
\hline Total time (years) & 30 & Tenor of the loan facility \\
\hline $\begin{array}{l}\text { Strength of mean } \\
\text { reversion }\end{array}$ & 0.17 & The mean reversion speed of the spread \\
\hline Equilibrium rate & $0.13 \%$ & Equilibrium rate of the spread \\
\hline Volatility & $0.13 \%$ & As we will estimate the daily interest rate \\
Time Step & 0.0833 & $\begin{array}{l}\text { values, we have computed the time step } \\
\text { as the ratio between 30 years and } \\
\text { (assumed) 360 days in a year. }\end{array}$ \\
\hline
\end{tabular}

The parameters computed above represents inputs for the drift function (equation 1 above). This function is determining the interest rate shock, which is added to the previous interest rate (or, in case of the first forecast, the last known interest rate). Because of the limited computational power of Excel, only 50 scenarios were computed for up to 30 years ahead. The average of the 50 scenarios is the curve (in the following charts the light-orange line for EURIBOR $1 \mathrm{M}$ and dark-red line for EURIBOR 3M) used in the forecasts for our benchmark test.

Figure 1: EURIBOR 1M forecast results for 50 scenarios using Vasicekinterest rate model

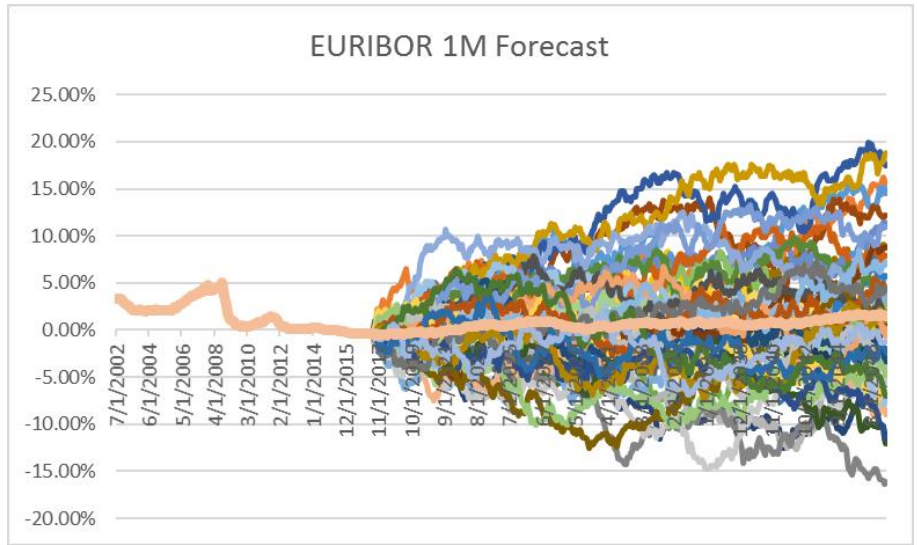


IFRS 9 Benchmarking Test: Too Complicated to Worth Doing It?

Figure 2: EURIBOR 3M forecast results for 50 scenarios using Vasicek interest rate model

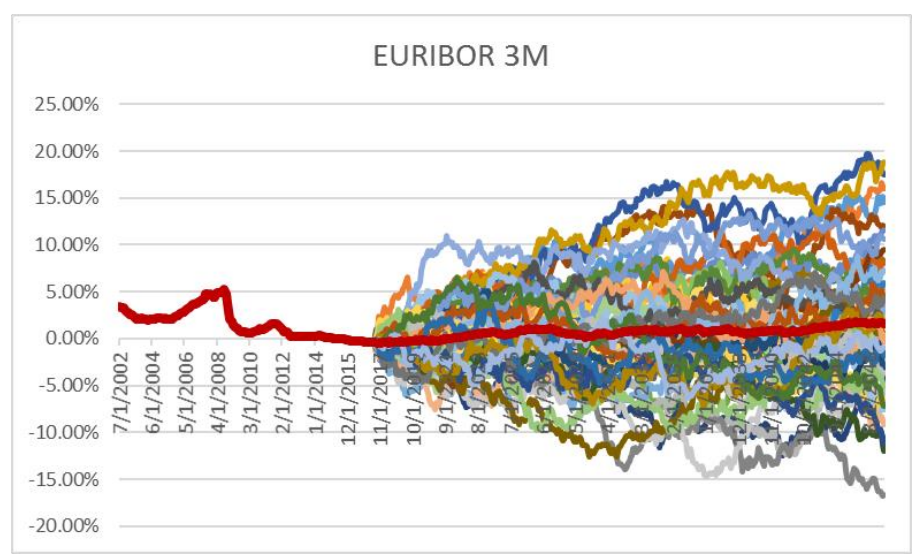

The results of the forecast then used into the analysis tool for determining the benchmark test.

\section{Analysis of the results and interpretation}

\section{Historical period between origination date and 31 December 2017}

The interest charged on this retail loan for the respective period of EUR $59,090.08$ (determined using the interest rate of EURIBOR $3 \mathrm{M}+2.5 \%$ ) is compared with EUR 56,638.42 (determined using the interest rate of EURIBOR $1 \mathrm{M}+2.5 \%)^{3}$, resulting in a difference of EUR 2,451.66, representing $4.1 \%$ difference in total interest charged in the respective period.

\section{Forward interest rates}

The resulting figures of our benchmark test tool developed show a relatively small difference between the total interest of the modified interest versus the interest of the benchmark instrument: EUR 3,387.47 in total interest charged, representing $3.79 \%$ from the total interest charged and only $1.54 \%$ from the total cash-flows (principal + interest) generated by this loan.

3We have floored the EURIBOR 1M, respectively EURIBOR 3M to zero for this computation (for the periods in which EURIBOR dropped below zero). 
Maria - Monica (Haralambie) Popescu, Bogdan - Stefan Ionescu

Table 4: Results of benchmark test using forward interest rates (benchmark instrument)

\section{EURIBOR 1M}

\begin{tabular}{|l|c|c|}
\hline & & $\begin{array}{l}\text { Total period } \\
\text { (in EUR) }\end{array}$ \\
\hline Loan Repayment & & 216,092 \\
\hline Total Interest Charged & $2.5 \%+E U R I B O R ~ 1 \mathrm{M}$ & 86,092 \\
\hline Benchmark & EURIBOR 1M & 28,675 \\
\hline Fixed spread & $2.5 \%$ & 57,417 \\
\hline & & \\
\hline Capital Repaid & & 130,000 \\
\hline
\end{tabular}

Table 5: Results of benchmark test using forward interest rates (modified instrument)

\section{EURIBOR 3M}

\begin{tabular}{|l|c|c|}
\hline & & $\begin{array}{l}\text { Total period } \\
\text { (in EUR) }\end{array}$ \\
\hline Loan Repayment & & 219,479 \\
\hline Total Interest Charged & $2.5 \%+E U R I B O R 3 \mathrm{M}$ & 89,479 \\
\hline Benchmark & EURIBOR 3M & 31,765 \\
\hline Fixed spread & $2.5 \%$ & 57,714 \\
\hline & & \\
\hline Capital Repaid & & 130,000 \\
\hline
\end{tabular}


IFRS 9 Benchmarking Test: Too Complicated to Worth Doing It?

Table 6: Comparison between the results of benchmark test using forward interest rates (benchmark instrument vs. modified instrument)

EURIBOR 1M vs. EURIBOR 3M

\begin{tabular}{|l|c|}
\hline \multicolumn{1}{|c|}{ Ratios } & Total Period \\
\hline Difference in total interest charged (EUR) & 3,387 \\
\hline Difference in Benchmark CF (EUR) & 3,090 \\
\hline $\begin{array}{l}\text { Difference in total interest charged/2.5\%+EURIBOR3M } \\
\text { Interest Charged }\end{array}$ & $3.79 \%$ \\
\hline $\begin{array}{l}\text { Difference in total interest charged/2.5\%+EURIBOR1M } \\
\text { Interest Charged }\end{array}$ & $3.93 \%$ \\
\hline $\begin{array}{l}\text { Difference in total interest charged/2.5\%+EURIBOR3M } \\
\text { Loan Repayment }\end{array}$ & $1.54 \%$ \\
\hline $\begin{array}{l}\text { Difference in total interest charged/2.5\%+EURIBOR1M } \\
\text { Loan Repayment }\end{array}$ & $1.57 \%$ \\
\hline $\begin{array}{l}\text { Difference in total interest charged/EUR Loan Principle } \\
\text { Amount }\end{array}$ & $2.61 \%$ \\
\hline
\end{tabular}

\section{Vasicek interest rate model}

The resulting figures using the Vasicek interest rate model are consistent with the ones determined using forward interest rates, showing a relatively small difference between the total interest of the modified interest versus the interest of the benchmark instrument: EUR 3,088.98 in total interest charged, representing $3.72 \%$ from the total interest charged and only $1.45 \%$ from the total cash-flows (principal + interest) generated by this loan.

Table 7: Results of benchmark test using Vasicek interest rate model (benchmark instrument)

EURIBOR 1M

\begin{tabular}{|l|l|c|}
\hline & & $\begin{array}{l}\text { Total period } \\
\text { (in EUR) }\end{array}$ \\
\hline Loan Repayment & & 209,847 \\
\hline & & \\
\hline Total Interest Charged & $2.5 \%+E U R I B O R ~ 1 M$ & 79,847 \\
\hline
\end{tabular}


Maria - Monica (Haralambie) Popescu, Bogdan - Stefan Ionescu

\begin{tabular}{|l|c|c|}
\hline Benchmark & EURIBOR 1M & 22,703 \\
\hline Fixed spread & $2.5 \%$ & 57,144 \\
\hline Capital Repaid & & \\
\hline
\end{tabular}

Table 8: Results of benchmark test using Vasicek interest rate model (modified instrument)

\section{EURIBOR 3M}

\begin{tabular}{|l|c|c|}
\hline & & $\begin{array}{l}\text { Total period } \\
\text { (in EUR) }\end{array}$ \\
\hline Loan Repayment & & 212,936 \\
\hline Total Interest Charged & $2.5 \%+E U R I B O R ~ 3 M$ & 82,936 \\
\hline Benchmark & EURIBOR 3M & 25,519 \\
\hline Fixed spread & $2.5 \%$ & 57,417 \\
\hline & & \\
\hline Capital Repaid & & 130,000 \\
\hline
\end{tabular}

Table 9: Comparison between the results of benchmark test using Vasicek interest rate mdeo (benchmark instrument vs. modified instrument)

EURIBOR 1M vs. EURIBOR 3M

\begin{tabular}{|l|c|}
\hline \multicolumn{1}{|c|}{ Ratios } & Total Period \\
\hline Difference in total interest charged (EUR) & 3,089 \\
\hline Difference in Benchmark CF (EUR) & 2,816 \\
\hline $\begin{array}{l}\text { Difference in total interest charged/2.5\%+EURIBOR3M } \\
\text { Interest Charged }\end{array}$ & $3.72 \%$ \\
\hline $\begin{array}{l}\text { Difference in total interest charged/2.5\%+EURIBOR1M } \\
\text { Interest Charged }\end{array}$ & $3.87 \%$ \\
\hline
\end{tabular}


IFRS 9 Benchmarking Test: Too Complicated to Worth Doing It?

\begin{tabular}{|l|c|}
\hline $\begin{array}{l}\text { Difference in total interest charged/2.5\%+EURIBOR3M } \\
\text { Loan Repayment }\end{array}$ & $1.45 \%$ \\
\hline $\begin{array}{l}\text { Difference in total interest charged/2.5\%+EURIBOR1M } \\
\text { Loan Repayment }\end{array}$ & $1.47 \%$ \\
\hline $\begin{array}{l}\text { Difference in total interest charged/EUR Loan Principle } \\
\text { Amount }\end{array}$ & $2.38 \%$ \\
\hline
\end{tabular}

\section{Conclusion}

Our aim for this paper was to present two different modelling methods for performing the quantitative assessment of an instrument from the IFRS 9 benchmark test perspective. We have also observed the difference in interest charged for an historical period, in order to assess the significance of the modification of the time-value-of-money component for a retail mortgage loan.

The results of our test revealed that the analysis using forward interest rates on one hand and Vasicek interest rate model, on the other for an instrument with a long tenor (30 years in this case) are quite similar, showing that using either one or the other will reach to similar conclusions for the analyzed instrument. This conclusion is consistent with the evolution of the EURIBOR interest rates in the last decades and the anticipations of the economists for these rates, given that the spread between EURIBOR $1 \mathrm{M}$ and EURIBOR $3 \mathrm{M}$ is quite small during the analyzed period (between 2002 and 2047).

Moreover, the conclusion of whether the analyzed instrument should continue to be measured under IFRS 9 at amortised cost or should be fair valued will depend on the thresholds defined by the credit institution, considering that for one entity a change of $2 \%$ can be considered significant, while for the other not.

Our analysis has some limitations, as we have considered only two modelling methods, based on the idea of past information used for forecasting the future interest rates, which cannot rise indefinitely. However, there are other models, such as the Displaced Diffusion Libor Market Model with Stochastic Volatility, which can be used to perform this quantitative assessment and can describe even better the dynamics of the underlying interest rates.

Future research will be focusing on other challenges brought by IFRS 9, such as incorporating forward-looking information into impairment parameters and the approaches to weighting of multiple scenarios. 
Maria - Monica (Haralambie) Popescu, Bogdan - Stefan Ionescu

\section{REFERENCES}

[1] Blanco, C., Soronow, D. (2001), Mean Reverting Process-Energy Price Processes Used for Derivatives Pricing and Risk Management. Commodities Now September: 68-72;

[2] Cefis, L.A. (2017), Testing for Convexity Relevance: An IFRS 9 Benchmark Cashflow Test Proposal. Working Paper Available at SSRN:

https://ssrn.com/abstract=2969122 or http://dx.doi.org/10.2139/ssrn.2969122;

[3] Cefis, L.A., Eliezer, D. (2017), Testing for Convexity Relevance: An IFRS 9

Benchmark Cashflow Test Proposal (with Stochastic Volatility). Available at SSRN:https://ssrn.com/abstract=3042661 or http://dx.doi.org/10.2139/ssrn.3042661;

[4] Chang, C.K., Chang, T. (2012), The Impact of Structural Change on the Calibration of Interest Rates Models in Taiwan. Economic Computation and Economic Cybernetics Studies and Research; Vol. 46, Issue 4, pp. 121-142;

[5] G20 (2009), Declaration on Strengthening the Financial System - London Summit, 2 April 2009;

[6] Hronsky, J. (2010), IFRS 9, Impairment and Procyclicality: Is the Cure Worse than the Disease?. Journal of the Securities Institute of Australia, pp. 5559 ;

[7] Huian, M. C. (2012), Accounting for Financial Assets and Financial Liabilities According to IFRS 9. Scientific Annals of the "AlexandruIoanCuza" University of Iaşi;Economic Sciences 59 (1), 27-47;

[8] Nobes, C., Stadler, C. (2013), How Arbitrary Are International Accounting Classifications? Lessons from Centuries of Classifying in Many Disciplines, and Experiments with IFRS Data. Accounting, Organizations and Society, Volume 38, Issue 8, November 2013, Pages 573-595;

[9] Page, M. (2014), Business Models as a Basis for Regulation of Financial Reporting. Journal of Management \& Governance, Volume 18, Issue 3, pp 683695. 